\title{
Limits of Intentionality
}

\section{An Interdisciplinary Approach}

\author{
Frank Wieber ${ }^{1}$, Peter M. Gollwitzer ${ }^{1,2}$, and Gottfried Seebaß ${ }^{3}$ (Guest Editors) \\ ${ }^{1}$ Department of Psychology, University of Konstanz, Germany, ${ }^{2}$ Department of Psychology, New York \\ University, USA, ${ }^{3}$ Department of Philosophy, University of Konstanz, Germany
}

How do people control their actions in order to serve their needs, desires, and goals? The fundamentals of intentional action control are a continuing topic of debate in social psychological research (e.g., Bargh, 2005; Bargh, Gollwitzer, \& Oettingen, 2010; Baumeister, Masicampo, \& Vohs, in press; Hofmann, Friese, \& Strack, 2009; Morsella, Bargh, \& Gollwitzer, 2009; Wegner, 2002) as well as in philosophy (e.g., Bratman, 1999; Dennett, 1987; Holton, 2009; Mele, 2009; Roughley, 2008; Searle, 1983; Seebaß, 1993). Whereas previous psychological research focused more on the effects of the strength and the content of intentions on the success of action control (e.g., Bandura, 1997; Dweck, 1996; Fishbein \& Ajzen, 1975; Higgins, 1997; Locke \& Latham, 1990; Ryan \& Deci, 2000), in recent years the focus has shifted to processes relevant to intentional action control (e.g., Baumeister, Vohs, \& Tice, 2007; Brehm \& Self, 1989; Carver \& Scheier, 1998; Gendolla, Brinkmann, \& Richter, 2007; Gollwitzer, 1999; Kuhl, 2000; Oettingen, Pak, \& Schnetter, 2001). As a consequence, the limits of intentionality have become a pressing research question: For example, how do a person's bad habits limit the formation and execution of intentions geared toward overcoming unwanted habitual responses? The emergence of data relevant to the limits of intentionality reveals a subject whose complexity calls for an interdisciplinary approach to enrich the conceptual and methodological perspective of social psychological research on intentionality (see Grammont, Legrand, \& Livet, 2010; van Lange, 2006; Vierkant, 2008).

The present special issue of Social Psychology therefore aspires to bring together characteristic perspectives from different disciplines in an analysis of the limits of intentional action control. The contributions in this special issue cover a broad range of research programs, comprising several theoretical and empirical contributions from the field of cognitive psychology, developmental psychology, and motivation psychology, as well as philosophy and neuroscience. A look at the 10 articles of this special issue quick- ly reveals the diversity of the different perspectives - as well as important conceptual and methodological similarities. Because we feel that the integration of different perspectives has the potential to propel research on the limits of intentionality, the articles of the special issue are organized along the comprehensive categories of conscious and unconscious action control.

There is a continuing debate about the contribution of conscious and unconscious processes to human action control. The central importance of unconscious processes for intentional action control has been highlighted in some accounts that conceptualize them as "sophisticated monitoring and control systems that can guide behavior over extended periods of time in a changing environment, in pursuit of desired goals" (Bargh, 2005, p. 43). The importance of conscious processes for intentional action control has been emphasized by research investigating the importance of conscious thought for successful action control (see Baumeister et al., in press). Significantly, the articles in this special issue neither overstate the power of conscious control of action - as sometimes has been the case in the European rationalist tradition and in cognitive psychology as well (e.g., Loftus \& Klinger, 1992) - nor do they draw an overly pessimistic picture of conscious action control - as seen in psychoanalysis and certain forms of behaviorism (e.g., Skinner, 1938). We feel that the concept of intentional action control as a mixture of conscious and unconscious processing opens an avenue to new empirical and conceptual research questions that have the potential to propel research on the limits of intentionality beyond traditional dual-process views.

\section{Overview of the Special Issue}

We organized the articles of the special issue according to the following criteria: Does the article focus primarily on the limits of conscious action control (including control 
over automatic processes), on the limits of unconscious action control, or on the limits of both conscious and unconscious action control?

\section{Conscious Thought Impacts Action Control}

The first four articles by McCrea and Hirt (2011), Epstude and Roese (2011), Unger and Stahlberg (2011), and Wieber, Suchodoletz, Heikamp, Trommsdorff, and Gollwitzer (2011) address whether and how different manipulations involving conscious thoughts impact the limits of action control as measured by dependent measures that also involve conscious thoughts. Manipulations comprise such diverse thought contents as self-affirming thoughts, counterfactuals geared at intention formation, conscious modification of automated responses, and intentional if-then planning. Dependent measures extend from performance on math tests or classification tasks to investment decisions.

McCrea and Hirt (2011) address whether same-domain self-affirmation is effective at overcoming "self-handicapping" behavior. Self-handicapping describes the phenomenon by which people sabotage the pursuit of their achievement goals in order to create excuses for potential failure that serve to protect a cherished self-view. More specifically, the authors tested whether the strategy to affirm the self in the same-domain (e.g., by recalling an event in which one succeeded in the domain) is effective at overcoming such limiting self-handicapping behavior. Results of two studies revealed that related-domain self-affirmation (e.g., with regard to performance in nonverbal logical reasoning and math tasks) has, in fact, the opposite effect on action control: Participants self-handicapped more when they engaged in related-domain self-affirmation, relative to unrelated-domain self-affirmation and no self-affirmation control participants. These results are in line with the selfstandards model (SSM; Stone \& Cooper, 2001) of cognitive dissonance, which postulates that positive information about the self may not always serve to inspire, but can instead serve as a standard against which current behavior will be compared.

Epstude and Roese (2011) review and explore whether linking research on counterfactual thoughts (i.e., thoughts about alternatives to factual actions and outcomes) to research on action control can advance our understanding of the limits of action control and apply it to real-life situations. Based on their functional theory of counterfactual thinking, distinct new hypotheses concerning the effects of counterfactual thinking on action control are developed and first empirical evidence is reviewed. On the "content-specific" route, counterfactuals are connected to the formation of intentions directed at effectively continuing goal striving. As counterfactuals predominantly occur in response to failed goal pursuits, they are thus assumed to serve a preparative function for future goal pursuits. On the "contentneutral" route, counterfactuals affect action control by im- pacting mindsets, regulatory focus, and motivation rather than by specific intentions. The authors also discuss the influence of a number of moderators of the link between counterfactuals and intentions that have been identified in the goal literature.

Unger and Stahlberg (2011) address the research question of whether conscious self-regulation (i.e., overriding automatic response tendencies) resulting in ego-depletion (Baumeister, Bratslavsky, Muraven, \& Tice, 1998) limits the intentionality of subsequent risk behavior (i.e., choosing an option that will result in an adverse outcome with a certain probability). Results of three experiments support the hypotheses that being ego-depleted (induced by relearning word meanings or suppressing emotions) increases the avoidance of risky behavior options. These results cannot be explained by reduced rationality of choices (as measured by expected values) or by the increased impact of a personal disposition to risk-taking; rather, they are in line with the assumption that people under ego-depletion choose less risky behavior options as they feel that they have insufficient self-regulation resources to cope with the potential negative outcomes of a risky decision.

Wieber et al. (2011) investigate the effectiveness of conscious if-then planning ("implementation intentions") to push forward the limits of action control in 6-year-old children. Goal intentions to ignore distractions were sufficient to successfully ignore distractions of low attractiveness. However, successfully shielding children's performance in an ongoing categorization task from moderately or highly attractive distractions required distraction-inhibiting implementation intentions ("If a distraction comes up, then I will ignore it!"). Also, improved task shielding as indicated by faster responses to an ongoing categorization task were found for if-then plans even when highly attractive distractions were presented out of children's line of sight. Shorter periods of looking at the external distraction in the implementation intention condition support the assumed automation of action control by implementation intentions.

\section{Conscious Thought Impacts Automatic Action Control}

Vogt, De Houwer, and Moors (2011) and Rothermund (2011) explore whether and how conscious intentions impact unconscious action control processes as measured by modified spatial cueing tasks and several other response time measures.

Vogt et al. (2011) consider the limits of automatic processes in the service of conscious action control by testing the flexibility and specificity of automatic attentional responses to goal-relevant stimuli (e.g., "boat" was explicitly mentioned in the instructions and required a response) relative to goal-related stimuli (e.g., "ship" was not mentioned in the instructions and required no response), and goal-unrelated stimuli (e.g., "stripe" was explicitly mentioned in 
the instructions, but it was not related to any goal words, and it also required no response). A spatial cueing paradigm was combined with a second word recognition task in a task-switching paradigm. As the intention to respond to specific goal-relevant words only related to the word recognition task, the presence of goal-relevant words during the spatial cueing paradigm allowed measurement of whether the intention concerning the word recognition task would impact responses in the spatial cueing paradigm, and whether these effects were limited to goal-relevant words or also generalized to goal-related words. The results showed that the intention concerning the word recognition task led to a focusing of attention on goal-relevant words but not goal-related words in the spatial cueing task. For goal-relevant events, uncompleted conscious intentions thus seem to guide automatic action control processes, even when a different intention is relevant for successful action control.

Rothermund (2011) discusses automatic processes in the service of action control by reviewing findings on two basic principles that govern the motivational regulation of automatic affective processing: the counterregulation principle and the control-dependency principle. The counterregulation principle postulates that attention is automatically allocated to information that is opposite in valence to current motivational states (Rothermund, Voss, \& Wentura, 2008). For example, in a study by Wentura, Voss, and Rothermund (2009), negative distractor stimuli (Frowny) interfered with task performance when the highscore in a TETRIS game could be improved (positive outcome focus), whereas positive distractor stimuli (Smiley) interfered with task performance when the highscore in the TETRIS game could be lost (negative outcome focus). Failed counterregulation is assumed to represent a limitation on successful action control as motivation may escalate or overextend. The controldependency principle (Rothermund, Bak, \& Brandtstädter, 2005) holds that experiencing goal pursuit as something controllable is accompanied by problem-focused information processing (negativity bias), whereas experiencing a lack of control over important outcomes is accompanied by enhancement-focused information processing (positivity bias). The control-dependency principle of affective processing supports intentional action control by increasing persistent goal striving in the face of controllable challenges, and by facilitating the acceptance of a given uncontrollable situation and disengagement from blocked goals.

\section{Unconscious Processes Impact Action Control}

Pacherie (2011) and Kuhl and Quirin (2011) focus primarily on unconscious processes (i.e., nonconceptual motor representations, lower levels of psychological functioning, and different kinds of stress) and how they impact action control.
Pacherie (2011) explores conceptual limits in the research on intentional action control from a philosophical perspective by taking neuropsychological evidence into account. The article argues that conceptual representations do not suffice to make intentional actions fully intelligible and calls for representations of action whose content is nonconceptual in order to advance our understanding of the properties of these unconscious action control processes and their interactions with conscious action control processes. Nonconceptual representations are thereby assumed to serve intentional action control (i.e., executable concepts of nonconceptual representations of goal-directed movements can be acquired), but they also have the potential to bypass intentional action control because of their relative autonomy and their specific temporal constraints (stemming from their role in motor control).

Kuhl and Quirin (2011) describe the functional mechanisms underlying action control (and how they can be disrupted) from the perspective of personality systems interactions theory; again, neuropsychological evidence is taken into account. The seven levels of psychological functioning postulated by the theory are linked to the concept of free will (defined as self-determined decision-making). The degree of volitional freedom is assumed to increase with the complexity of the levels of psychological functioning (e.g., from habits, temperament, affect, and coping with stress to motives, specific goals, and global personal goals). Moreover, demand-related stress (i.e., uncompleted intentions, duties, or unpleasant tasks that typically reduce positive affect) is shown to limit the pursuit of specific goals, whereas threat-related stress (i.e., anxiety, uncertainty, or unexpected changes that typically elicit negative affect) is demonstrated to limit the generation of selfcongruent specific goals (specific goals that are compatible with one's global personal goals).

\section{Contrasting Conscious and Unconscious Action Control}

Finally, Suchodoletz and Achtziger (2011) and Schmitz (2011) review the concepts and empirical evidence on both conscious and unconscious action control and derive implications and pathways for further development as well as for the integration of different approaches.

Suchodoletz and Achtziger (2011) discuss psychological approaches to both conscious and unconscious action control and their limits. They first examine the development of goal-directed behavior in early childhood with respect to the different limits of children's action control, based on developmental and neuropsychological evidence. Evidence for distinct limits of action control by intentions is then discussed, integrating findings from motivation psychology, cognitive psychology, and biopsychology. Finally, the concepts of conscious and unconscious goal striving are compared and evidence is discussed, before suggestions are 
made on how psychological research might extend the limits of intentional action control.

Schmitz (2011) examines the limitations of the concept of conscious action control from a philosophical perspective. More specifically, Schmitz develops the argument that the dominant understanding of conscious action control is restricted by its limitation to conceptual contents. The article calls for an extension of the concept of consciousness to nonconceptual forms of consciousness such as emotions (e.g., experiencing eagerness) or motor experiences (e.g., the experience of raising one's arm). It is argued that in order to gain a comprehensive understanding of the independent and conjoint contribution of conscious and unconscious processes to action control, it is necessary to investigate the role of nonconceptual forms of consciousness. Implications of this conceptual extension for psychological and philosophical research are discussed.

Taken together, several limits of both conscious and unconscious processes of intentional action control are identified by the articles of this special issue as well as different strategies for how to overcome these limits (which themselves face limitations). In addition, limits of the conceptual approach to both conscious and unconscious action control processes are highlighted.

The analysis of the interplay between conscious and unconscious processes of action control also offers a promising starting point for the development of interventions to help push forward the limits of intentionality. Although people have only limited insights into the functioning of the unconscious processes that support or restrict their action control, they might be able to learn about their unconscious action control processes (e.g., by information about the impact of ego-depletion, self-handicapping, or implementation intentions) and engage in training tailored to the properties of unconscious action control principles. Building on the findings of McCrea and Hirt (2011), for instance, one could use unrelated domain self-affirmations to reduce the likelihood of self-handicapping behavior; or planning in an if-then format (implementation intentions; Wieber et al., 2011). could be used to change action control from effortful action control by goal intentions to automatic goaldependent action control by if-then plans. The latter case is particularly intriguing as implementation intentions are formed by a conscious act of will but have automatic consequences (i.e., delegation of action control to situational cues).

We hope that the assembly of different perspectives on the limits of intentionality in this special issue will contribute to the understanding of both the conscious intentions and the unconscious processes underlying action control as well as their interactions. Finally, we would like to thank all colleagues who submitted their papers for consideration to this special issue, the reviewers for their dedicated work, and Lily-Maria Silny from the editorial office and the editor Gerd Bohner for their support of our endeavor. We hope that the articles of this special issue will inspire and ener- gize further conceptual and empirical research to push the limits of intentionality even further.

\section{Acknowledgments}

This research was supported by the German Science Foundation (DFG) to the research group "Limits of Intentionality" (582).

\section{References}

Bandura, A. (1997). Self-efficacy: The exercise of control. New York: Freeman.

Bargh, J.A. (2005). Bypassing the will: Toward demystifying the nonconscious control of social behavior. In R. R. Hassin, J.S. Uleman \& J.A. Bargh (Eds.), The new unconscious (pp. 37-58). New York: Oxford University Press.

Bargh, J. A., Gollwitzer, P. M., \& Oettingen, G. (2010). Motivation. In S. T. Fiske, D. T. Gilbert \& G. Lindzey (Eds.), Handbook of social psychology (pp. 268-316). New York: Wiley.

Baumeister, R.F., Bratslavsky, E., Muraven, M., \& Tice, D. M. (1998). Ego depletion: Is the active self a limited resource? Journal of Personality and Social Psychology, 74, 1252-1265.

Baumeister, R. F., Masicampo, E. J., \& Vohs, K. D. (in press). Do conscious thoughts cause behavior? Annual Review of Psychology.

Baumeister, R. F., Vohs, K. D., \& Tice, D. M. (2007). The strength model of self-control. Current Directions in Psychological Science, 16, 351-355.

Bratman, M. (1999). Intention, plans, and practical reason. Stanford, CA: Center for the Study of Language and Information.

Brehm, J.W., \& Self, E. A. (1989). The intensity of motivation. Annual Review of Psychology, 40, 109-131.

Carver, C. S., \& Scheier, M.F. (1998). On the self-regulation of behavior. New York: Cambridge University Press.

Dennett, D.C. (1987). The intentional stance. Cambridge, MA: MIT.

Dweck, C. S. (1996). Implicit theories as organizers of goals and behavior. In P. M. Gollwitzer \& J. A. Bargh (Eds.), The psychology of action: Linking cognition and motivation to behavior (pp. 69-90). New York: Guilford.

Epstude, K., \& Roese, N. J. (2011). When goal pursuit fails: The functions of counterfactual thoughts in intention formation. Social Psychology, 42, 19-27.

Fishbein, M., \& Ajzen, I. (1975). Belief, attitude, intention, and behavior: An introduction to theory and research. Reading, MA: Addison-Wesley.

Gendolla, G. H. E., Brinkmann, K., \& Richter, M. (2007). Mood, motivation, and performance: An integrative theory, research, and applications. In M.L. Andrew (Ed.), Mood and human performance: Conceptual, measurement and applied issues. (pp. 35-61). Hauppauge, NY: Nova Science Publishers.

Gollwitzer, P.M. (1999). Implementation intentions: Strong effects of simple plans. American Psychologist, 54, 493-503.

Grammont, F., Legrand, D., \& Livet, P. (2010). Naturalizing intention in action. Cambridge, MA: MIT. 
Higgins, E. T. (1997). Beyond pleasure and pain. American Psychologist, 52, 1280-1300.

Hofmann, W., Friese, M., \& Strack, F. (2009). Impulse and selfcontrol from a dual-systems perspective. Perspectives on Psychological Science, 4, 162-176.

Holton, R. (2009). Willing, wanting, waiting. New York: Oxford University Press.

Kuhl, J. (2000). A functional-design approach to motivation and self-regulation: The dynamics of personality systems and interactions. In M. Boekaerts, P. R. Pintrich \& M. Zeidner (Eds.), Handbook of self-regulation (pp. 111-169). San Diego, CA: Academic Press.

Kuhl, J., \& Quirin, M. (2011). Seven steps toward freedom and two ways to lose it: Overcoming limitations of intentionality through self-confrontational coping with stress. Social Psychology, 42, 74-84.

Locke, E. A., \& Latham, G. P. (1990). A theory of goal setting and task performance. Englewood Cliffs, NJ: Prentice-Hall.

Loftus, E. F., \& Klinger, M.R. (1992). Is the unconscious smart or dumb? American Psychologist, 47, 761-765.

McCrea, S. M., \& Hirt, E. R. (2011). Limitations on the substitutability of self-protective processes: Self-handicapping is not reduced by related-domain self-affirmations. Social Psychology, 42, 9-18.

Mele, A. R. (2009). Effective Intentions: The power of conscious will. New York: Oxford University Press.

Morsella, E., Bargh, J. A., \& Gollwitzer, P.M. (2009). Oxford handbook of human action. New York: Oxford University Press.

Oettingen, G., Pak, H., \& Schnetter, K. (2001). Self-regulation of goal-setting: Turning free fantasies about the future into binding goals. Journal of Personality and Social Psychology, 80, 736-753.

Pacherie, E. (2011). Nonconceptual representations for action and the limits of intentional control. Social Psychology, 42, 67-73.

Rothermund, K. (2011). Counterregulation and control-dependency: Affective processing biases in the service of action regulation. Social Psychology, 42, 56-66.

Rothermund, K., Bak, P. M., \& Brandtstädter, J. (2005). Biases in self-evaluation: Moderating effects of attribute controllability. European Journal of Social Psychology, 35, 281-290.

Rothermund, K., Voss, A., \& Wentura, D. (2008). Counterregulation in affective attentional biases: A basic mechanism that warrants flexibility in emotion and motivation. Emotion, 8, $34-46$.

Roughley, N. (2008). Wanting and intending. Dordrecht: Spring-

Ryan, R. M., \& Deci, E. L. (2000). Self-determination theory and the facilitation of intrinsic motivation, social development, and well-being. American Psychologist, 55, 68-78.

Schmitz, M. (2011). Limits of the conscious control of action. Social Psychology, 42, 93-98.

Searle, J. R. (1983). Intentionality, an essay in the philosophy of mind. Cambridge, UK: Cambridge University Press.

Seebaß, G. (1993). Wollen [Willing]. Frankfurt: Klostermann.

Skinner, B. F. (1938). The behavior of organisms: An experimental analysis. New York: D. Appleton-Century Co.

Stone, J., \& Cooper, J. (2001). A self-standards model of cognitive dissonance. Journal of Experimental Social Psychology, 37, 228-243.

Suchodoletz, A. v., \& Achtziger, A. (2011). Intentions and their limits: Perspectives in psychological science. Social Psychology, 42, 85-92.

Unger, A., \& Stahlberg, D. (2011). Ego-depletion and risk behavior: Too exhausted to take a risk. Social Psychology, 42, 28-38.

van Lange, P.A.M. (2006). Bridging social psychology. In P. A. M. van Lange (Ed.), Bridging social psychology: Benefits of transdisciplinary approaches (pp. 3-20). Mahwah, NJ: Erlbaum.

Vierkant, T. (Ed.). (2008). Willenshandlungen - Zur Natur und Kultur der Selbststeuerung [Willful behavior - On the nature and culture of self-regulation]. Frankfurt am Main: Suhrkamp.

Vogt, J., De Houwer, J., \& Moors, A. (2011). Unintended allocation of spatial attention to goal-relevant but not to goal-related events. Social Psychology, 42, 48-55.

Wegner, D. M. (2002). The illusion of conscious will. Cambridge, MA: MIT.

Wentura, D., Voss, A., \& Rothermund, K. (2009). Playing TETRIS for science. Counterregulatory affective processing in a motivationally "hot" context. Acta Psychologica, 131, 171-177.

Wieber, F., Suchodoletz, A. v., Heikamp, T., Trommsdorff, G., \& Gollwitzer, P.M. (2011). If-then planning helps school-aged children to ignore attractive distractions. Social Psychology, $42,39-47$.

Frank Wieber

Department of Psychology

University of Konstanz

D-78457 Konstanz

Germany

Tel. +497531882877

Fax +497531883286

E-mail frank.wieber@uni-konstanz.de 